\title{
SELECTIVE CYCLOOXYGENASE-2 INHIBITION PROTECTS AGAINST MYOCARDIAL DAMAGE IN EXPERIMENTAL ACUTE ISCHEMIA
}

\author{
Alberto Carnieto Jr., Paulo Magno Martins Dourado, Protásio Lemos da Luz, \\ Antonio Carlos Palandri Chagas
}

doi: $10.1590 / \mathrm{S1807-59322009000300016}$

Carnieto Jr. A, Dourado PMM, da Luz PL, Chagas ACP. Selective cyclooxygenase-2 inhibition protects against myocardial damage in experimental acute ischemia. Clinics. 2009;64(3):245-52.

BACKGROUND: Acute myocardial infarction is associated with tissue inflammation. Early coronary reperfusion clearly improves the outcome but may help propagate the inflammatory response and enhance tissue damage. Cyclooxygenase- 2 is an enzyme that catalyzes the initial step in the formation of inflammatory prostaglandins from arachidonic acid. Cyclooxygenase- 2 levels are increased when ischemic cardiac events occur. The overall function of COX-2 in the inflammatory process generated by myocardial ischemic damage has not yet been elucidated.

GOAL: The objective of this study was to determine whether a selective cyclooxygenase-2 inhibitor (rofecoxib) could alter the evolution of acute myocardial infarction after reperfusion.

METHODS AND RESULTS: This study was performed with 48 mongrel dogs divided into two groups: controls and those treated with the drug. All animals were prepared for left anterior descending coronary artery occlusion. The dogs then underwent 180 minutes of coronary occlusion, followed by 30 minutes of reperfusion. Blood samples were collected from the venous sinus immediately before coronary occlusion and after 30 minutes of reperfusion for measurements of CPK-MB, CPK-MBm and troponin I. During the experiment we observed the mean blood pressure, heart rate and coronary flow.

The coronary flow and heart rate did not change, but in the control group, there was blood pressure instability, in addition to maximal levels of CPK-MB post-infarction. The same results were observed for CPK-MBm and troponin I.

CONCLUSION: In a canine model of myocardial ischemia-reperfusion, selective inhibition of Cyclooxygenase-2 with rofecoxib was not associated with early detrimental effects on the hemodynamic profile or the gross extent of infarction; in fact, it may be beneficial by limiting cell necrosis.

KEYWORDS: Coronary Reperfusion; Cyclooxygenase-2; Troponin; Myocardial Infarction; Rofecoxib.

\section{INTRODUCTION}

Acute myocardial ischemic injury is associated with various pathophysiological responses, including inflammatory activity with migration of neutrophils to the ischemic site. Although early blood reperfusion to the ischemic myocardium is undoubtedly beneficial in the setting

Atherosclerosis Unit, Instituto do Coração (InCor), Hospital das Clínicas, Faculdade de Medicina, Universidade de São Paulo - São Paulo/SP, Brasil Tel.: 55113069.5352

Email: albertocarnieto@gmail.com

Received for publication on August 31, 2008

Accepted for publication on December 05, 2008 of acute myocardial infarction, there is much evidence that re-establishment of coronary blood flow helps propagate inflammatory processes, enhancing tissue destruction and contributing to myocardial dysfunction. ${ }^{1,2}$

Attempts to limit myocardial necrosis and improve outcomes in acute myocardial infarction by modulating the inflammatory process have long been proposed. Around thirty years ago, investigators demonstrated that some, but not all, anti-inflammatory agents could reduce the size of myocardial infarction in laboratory animals. ${ }^{3}$ On the other hand, no clear benefits and even evidence of deleterious effects were seen in human studies of anti-inflammatory drugs in acute coronary syndromes, ${ }^{4-7}$ although meloxicam was associated with a better outcome in a small trial. ${ }^{8}$ 
More recently, with the advent of selective cyclooxygenase (COX)-2 inhibitors, the issue of anti-inflammatory drugs in acute myocardial infarction has again been brought to the forefront. COX is an enzyme that converts free arachidonic acid into prostaglandins, which mediate inflammation. Differing from the COX-1 isoform, which is constitutively expressed and has a housekeeping role, COX-2 is usually absent or minimally present in most tissues but is induced under certain conditions such as inflammation. Indeed, COX2 is typically considered a pro-inflammatory enzyme, and selective COX-2 inhibitors have been widely prescribed for acute and chronic inflammatory disorders. Importantly, this class of drugs has been associated with adverse cardiac events in humans, raising serious concerns about their safety. ${ }^{9-13}$ The mechanisms by which COX-2 inhibitors may harm the heart have not been fully elucidated. It has been shown that under certain circumstances, COX-2 possesses other properties, including inhibition of fibrosis, thrombosis and even inflammation ${ }^{14-16}$ which may play a cardioprotective role.

Investigations focusing on COX-2 and COX-2 inhibitors in different models of myocardial ischemia/infarction in diverse animals have elicited contradictory findings, bringing more controversy to this issue. While several studies have shown that COX-2 inhibition protects the heart and preserves cardiac function in murine models of myocardial ischemia/ infarction, ${ }^{17-21}$ celecoxib was shown to deteriorate myocardial function and increase mortality after myocardial infarction in pigs. ${ }^{22}$

Importantly, these studies evaluated the consequences of complete ligation of a coronary artery, without reperfusion, on cardiac function over several days or weeks. In a clinical setting, early coronary reperfusion is not only desirable but also increasingly frequent, now that fibrinolytic therapy and percutaneous intervention have become more accessible. Moreover, it is known that it is during the first moments after an acute myocardial infarction that the subjects are the most susceptible to complications. The effects of COX-2 inhibition in the very early phase after an acute myocardial infarction with coronary reperfusion have not been well addressed. In rabbits, it appears that COX-2 has an essential role in cardioprotection conferred by ischemic preconditioning ${ }^{23}$; accordingly, COX-2 inhibition was shown to exacerbate ischemia-induced acute myocardial dysfunction in an in vitro perfused rabbit heart model. ${ }^{24}$

This study was designed to help elucidate the role of COX-2 and the mechanisms involved in the effect of selective COX-2 inhibitors in the very early phase of acute myocardial infarction followed by coronary reperfusion. Specifically, this study aimed to evaluate the effect of pretreatment with rofecoxib, a selective COX-2 inhibitor, on the extent of infarction, biomarkers of cardiac necrosis and hemodynamic behavior in a well-established canine model of myocardial ischemia-reperfusion.

\section{MATERIAL AND METHODS}

This study was approved by the Ethics in Research Committee of our institution (Protocol 2165/02/172), according to the American Heart Association regulations for Research Involving Animals, based on the "Guide for the Care and Use of Laboratory Animals" (National Health Council publication, National Academy Press, Washington, D.C 1996. ${ }^{6363 \mathrm{~A}}$

The dogs used in this experiment were obtained from the Public Health System, Urban Zoonosis Department. After being properly cleaned, the animals were housed in the biotery in isolated cages with veterinary care for several days before the surgery was carried out. They were fed commercial dog feed and water ad libitum, and they were vaccinated against rabies (hydrophobia) and given a dose of vermicide. Fortyeight adult male dogs (Canis familiaris) were studied: 28 dogs were part of the study group treated with commercial rofecoxib (Vioxx ${ }^{\circledR}$, MK-966) at a single 50-mg/day dose per $o s$ with their chow during the 48 hours preceding the surgical procedure, while $20 \mathrm{dogs}$ were part of the control group. The weight of the animals ranged from 15 to $30 \mathrm{~kg}$. Rofecoxib is rapidly absorbed after oral administration. In dogs, a peak concentration of $207 \mathrm{ng} / \mathrm{ml}(0.6585 \mu \mathrm{M})$ was achieved 2 to 3 hours after oral administration of a single $25-\mathrm{mg}$ dose. ${ }^{61-63}$

In both groups, the animals were anesthetized, intubated and artificially ventilated. They underwent thoracotomy and dissection of the anterior descending coronary artery. The following hemodynamic parameters were evaluated: coronary blood flow, average blood pressure and heart rate. Immediately before the occlusion, blood was collected from the venous sinus to evaluate creatine phosphokinase-MB (CPK-MB), CPK-MB mass and troponin-I levels. This procedure was followed by a 180-minute occlusion and a 30-minute reperfusion. After completing the 30-minute reperfusion, a new blood sample from the venous sinus was collected to evaluate the same biochemical markers.

At the end of each experiment, all dogs received a dose of $30 \mathrm{mg} / \mathrm{kg}$ of sodium pentobarbital before euthanasia with potassium chloride. Following this procedure, their hearts were excised and submitted to Evans blue and triphenyltetrazolium chloride staining to define the risk areas and areas of infarction.

\section{MONITORING AVERAGE BLOOD PRESSURE, HEART RATE AND CORONARY FLOW}

A 7F polyethylene catheter was positioned in the left 
carotid artery for continuous monitoring of the average blood pressure (ABP) and heart rate (HR). The catheter was connected to a Biopac Systems transducer, TSD-104 Model (Biopac Systems, Santa Barbara, CA, USA), linked to a computer with specific software (Acknowledge) to read the hemodynamic values. Central venous access was obtained through cannulation of the left internal jugular vein by means of another $7 \mathrm{~F}$ polyethylene catheter to infuse liquids and anesthetic.

Coronary flow was measured with placement of an electromagnetic flow-transducer (Transonic Systems Inc., Probe $2 \mathrm{~S}$ ) in the ADA in its proximal third, immediately after the emergence of the first diagonal branch.

\section{DETERMINING THE LEVELS OF CPK-MB, CPK- MB MASS AND TROPONIN I}

Quantitative determination of the MB isoform of creatine kinase was performed by means of in vitro immune assays, using an automatic analyzer Roche/Hitachi model 912 (Roche Diagnostics, Indianapolis, IN, USA)

This method presupposes that CK-MB is made up of two subunits: CK-M and CK-B, both with an active site. The test consists of adding a polyclonal antibody directed against the CK-M site to the serum, which almost completely (99.6\%) inhibits the catalytic ability of the CK-M subunit without affecting the CK-B subunit. The remaining activity of the CK-B subunit is equal to half of the activity of CK-MB. The catalytic activity of $\mathrm{CK}-\mathrm{MB}$ can be calculated as the measured CK-B activity multiplied by 2 , since the CK-BB isoform rarely appears in the serum. ${ }^{53,54}$

For the measurement of creatine kinase-MB mass, immunochemiluminescence with laboratory automation was used by means of "Immulite" DPC equipment (Diagnostic Products Corporation - Los Angeles, CA, USA). In this method, the serum is put into contact with small spheres covered by anti-CK-MB murine monoclonal antibody (Turbo CK-MB test unit - SCP1). A second test unit is then added (Turbo CK-MB - SCP2), containing alkaline phosphatase conjugated to an anti-CK-MB murine polyclonal antibody. Upon reacting, both units cause the release of luminescence, quantified by the Immulite equipment. ${ }^{55,56}$

For measurement of troponin I, immunochemiluminescence with laboratory automation was used by means of Immulite DPC equipment (Diagnostic Products Corporation - Los Angeles, CA, USA). In this method, the serum is put into contact with small spheres covered by antitroponin I rat monoclonal antibody (Turbo Troponin I - STI1 test unit). Thereafter, a second test unit (Turbo Troponin I STI2) is added, containing alkaline phosphatase conjugated with anti-troponin I goat polyclonal antibody. Upon reacting, both units cause the release of luminescence quantified by the Immulite equipment. ${ }^{55,56}$

\section{ANATOMIC DEFINITION OF THE NORMOPER- FUSED, ISCHEMIC AND INFARCTION AREAS}

The regions of the left ventricular myocardium with normoperfusion, ischemia and infarction were evaluated at the end of each experiment by the techniques described by Jolly et $\mathrm{al}^{57}$ and Chagas. ${ }^{58}$

At the end of the protocol, the hearts were excised. The ADA was then occluded at the same place in which the occlusor was positioned and cannulated distal to the occlusion. Evans blue stain (1 mg/kg) was infused through a catheter positioned in the right coronary artery and in the left coronary artery trunk, and simultaneously, a solution at 2\% CTT was injected into the ADA. Thus, the areas that were not perfused by the ADA were stained by Evans blue, delimiting the region at risk supplied by the ADA. The heart was then sectioned longitudinally and incubated in a CTT solution at $37^{\circ} \mathrm{C}$ for 30 minutes. This technique stains the viable myocardium in bright red and the necrotic tissue in a pale yellow shade. The regions that did not show a bright red color and remained a pale yellow shade were defined as necrotic myocardium..$^{59,60}$

\section{STATISTICAL ANALYSIS}

Initially, all variables were analyzed descriptively. With regard to the quantitative variables, analysis was carried out by observation of the minimum and maximum values and the calculation of averages and standard deviations. For the qualitative variables, absolute and relative frequencies were calculated.

To analyze the hypothesis of average equality between the two groups, a Student's t-test ${ }^{25}$ was used, which allows the evaluation of variables at a single period between the control and treated groups. This method was used to analyze the weight of the fragments of the left ventricle.

In the hemodynamic analysis of the groups, the Analysis of Variance (ANOVA) technique with repeated ${ }^{53}$ measurements was used, which consists of the adjustment of a multivariate linear model.

\section{RESULTS}

Initially, the study included 61 dogs, but 13 dogs were excluded because they exhibited ventricular fibrillation during the coronary artery occlusion. Electric cardioversion could not be used because it can alter serum levels of necrosis markers. 
The arterial blood pressure drop in the basal period as compared to the arterial blood pressure in the $1^{\text {st }}$ minute of occlusion showed a sharp drop $(\mathrm{p}<0.001)$ in both groups. There was a significant arterial blood pressure increase $(\mathrm{p}<0.001)$ between the $1^{\text {st }}$ and $30^{\text {th }}$ minute in the control group; however, this was not observed in the treated group $(\mathrm{p}=0.2257)$. It was also observed that the arterial blood pressure at the $30^{\text {th }}$ minute did not significantly differ from that at the $180^{\text {th }}$ minute, in either the control group $(\mathrm{p}=0.2576)$ or the treated group $(\mathrm{p}=0.0546)$. It was observed, however, that the arterial pressure at the $180^{\text {th }}$ minute differed from that at the $1^{\text {st }}$ minute of reperfusion in the control group ( $\mathrm{p}=0.0056$ ), while the same drop in pressure was not observed in the treated group $(\mathrm{p}=0.3973)$.

Using ANOVA with repeated measurements, we observed that both groups showed the same heart rate throughout the study period $(\mathrm{p}=0.1015)$. The groups did not show significant differences between their averages $(\mathrm{p}=0.2013)$ and showed the same significant changes throughout the study $(\mathrm{p}<$ 0.001 ), indicating that there was homogeneity in heart rate among the groups.

The two groups also showed the same cardiac flow behavior throughout the experiment $(\mathrm{p}=0.5315)$. They did not show significant differences between their averages $(\mathrm{p}=0.4118)$ and showed the same significant changes throughout the experiment $(\mathrm{p}<0.001)$. The basal period differed from the $1^{\text {st }}$ minute of reperfusion $(\mathrm{p}<0.001)$, and this differed from the $30^{\text {th }}$ minute of reperfusion $(\mathrm{p}<0.001)$ in both groups, showing that both groups had reactive hyperemia, characteristic of reperfusion.

No significant changes were observed in the normoperfused areas between the studied groups $(\mathrm{p}=0.1648)$. The same results were obtained for the ischemic areas $(\mathrm{p}=0.3651)$ and the infarction area $(\mathrm{p}=0.2793)$.

Using ANOVA with repeated measurements, we observed that the two groups showed a significant increase in CPKMB between pre- and post-infarction $(\mathrm{p}<0.001)$, indicating that both groups suffered acute myocardial infarction. The control group showed significantly higher averages of CPKMB than the treated group during the post-infarction period $(\mathrm{p}=0.0445)$ (Figure 1).

The control and treated groups showed a significant increase in the level of the CPK-MB mass between the preand post-infarction periods $(\mathrm{p}<0.001)$, with no difference between their averages during pre-infarction $(\mathrm{p}=0.2408)$. During the post-infarction period, however, we observed a significant $\mathrm{CPK}-\mathrm{MB}$ mass increase in the control group $(\mathrm{p}=0.007)$, as compared to the treated group (Figure 2).

The two groups showed a significant difference in troponin I levels during the pre- and post-infarction periods $(p<0.001)$. The groups showed no difference between

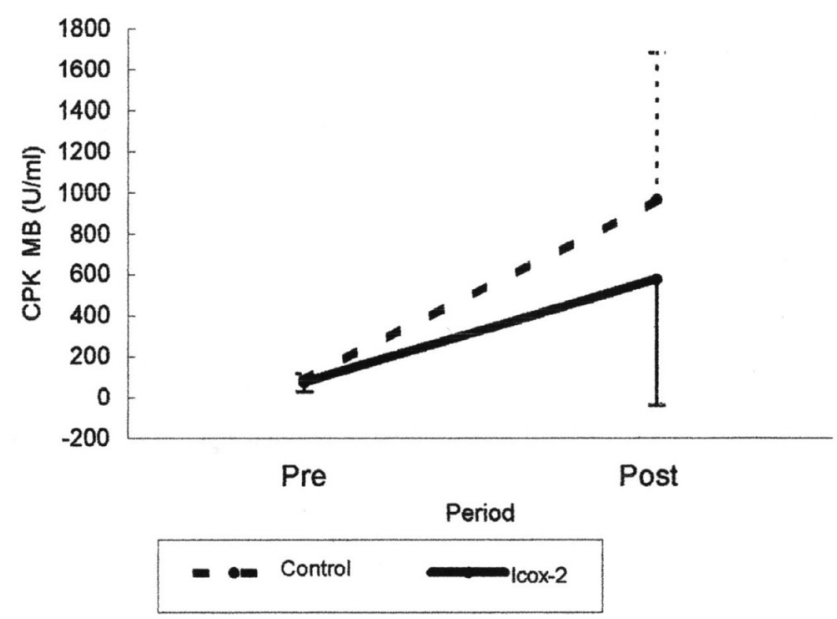

Figure 1 - Graph showing values of CPK-MB during the pre and postinfarction periods in the control dogs and in the dogs treated with icox-2

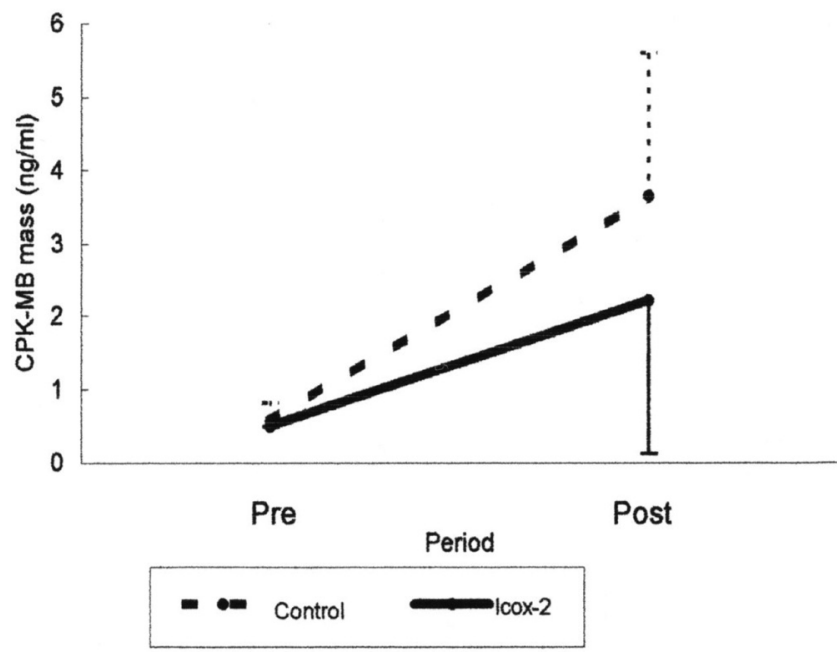

Figure 2 - Graph of the values of CPK-MB mass during the pre and post infarction periods in the control dogs and in the dogs treated with icox-2

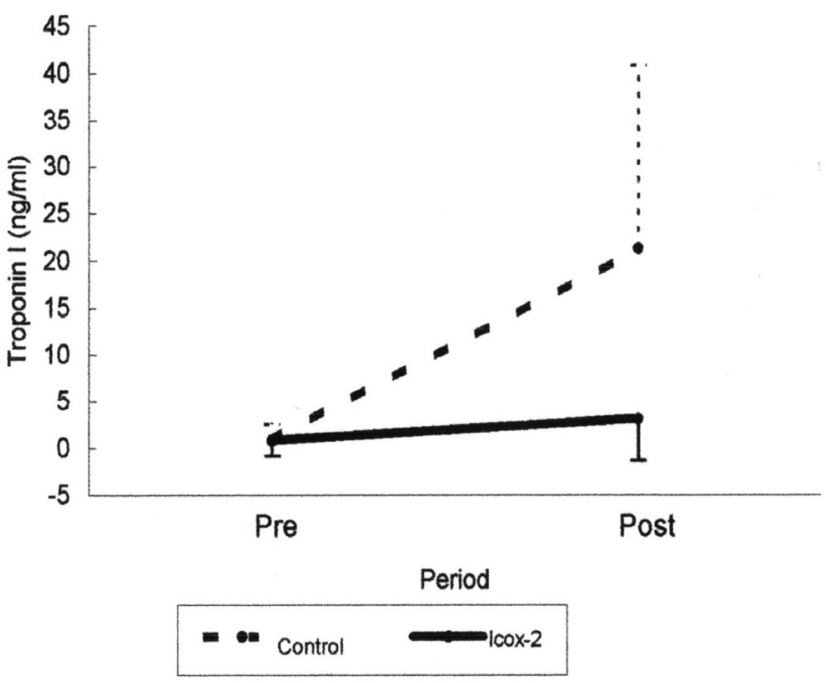

Figure 3 - Graph showing values of Troponin I during the pre and postinfarction periods in the control dogs and in the dogs treated with icox-2 
levels during pre-infarction $(\mathrm{p}=0.6275)$, but troponin I was increased in the control group $(\mathrm{p}<0.001)$ during the postinfarction period, as compared to the group treated with icox-2 (Figure 3).

\section{DISCUSSION}

The current study shows that the use of a specific cyclooxygenase- 2 inhibitor in experimental acute myocardial ischemia models results in a protective effect on cardiac muscle.

In the analysis of blood pressure, two periods of pressure instability were observed: one occurred during the period in which the coronary occlusion was performed (detected at $1 \mathrm{~min}$ ), and the other occurred during the period in which the coronary was reperfused (detected in the $1^{\text {st }}$ minute of reperfusion). This statistically significant pressure drop was only observed in the control group, as the treated group did not show arterial pressure instability during these two periods.

This effect of a selective cyclooxygenase- 2 inhibitor on the systolic, diastolic and average blood pressure has also been observed in other studies. ${ }^{26-28}$ The most commonly accepted hypothesis is related to the effect of sodium reabsorption by the kidneys when the cyclooxygenase- 2 inhibitor is administered, without affecting glomerular filtration.

In a recent study by Höcherl et al., ${ }^{29}$ cardiac dysfunction and blood pressure were evaluated in rats undergoing intravenous infusion of lipopolysaccharides. These animals were divided into two groups: the treated group received a specific cyclooxygenase-2 inhibitor (rofecoxib), and the control group was untreated. A significant decrease in blood pressure and myocardial dysfunction was observed in the control group. These pathological changes were not observed in the group treated with the COX-2 inhibitor. The blood pressure observations of Höcherl et al. ${ }^{29}$ were similar to those obtained in our experiment, in which the group treated with iCOX-2 did not show a sharp drop in blood pressure during the periods when the coronary occlusion and reperfusion were performed. Despite these results, the exact mechanism by which selective cyclooxygenase- 2 inhibitors interfere with blood pressure remains to be explained.

No changes in coronary flow were observed between the groups in our study. Our results were similar to those of a study by Verma et al.,$^{30}$ who used plethysmography in the forearm of volunteers and healthy patients to evaluate the use of rofecoxib, as compared to infusion of acetylcholine and sodium nitroprussiate. It was observed that the patients did not show blood flow changes, suggesting that the selective COX-2 inhibitor did not stop the vasodilatation mechanisms mediated by the endothelium.
In our biochemical analysis, we used the same methods used in clinical analysis laboratories for human measurements. Such methods are also valid for laboratory animals. ${ }^{31,32}$ Each animal served as its own control between the pre-infarction and the post-infarction period, and the obtained values were in accordance with those found in other studies. . $^{31,32}$

Considering the kinetics of the analyzed biochemical markers in the circulation (e.g., cell compartmentalization, linkage to plasma molecules, distribution, degradation and elimination), the subjects only have detectable plasma levels in the peripheral circulation from four to five hours after the coronary ischemic event. ${ }^{31}$ Due to the metabolic and distributive kinetics of CPK-MB, CPK-MB mass and troponin I, we collected blood samples by central venous access (from the coronary sinus) after 30 minutes of coronary reperfusion, i.e., three and a half hours after the start of the ischemic event. This allowed sufficient time ${ }^{33-}$ 35 to obtain detectable plasma levels by the biochemical methods used.

Previous studies ${ }^{36,37}$ making use of non-steroid antiinflammatories showed that these medications did not have a cardioprotective effect during ischemic injury, but there is still no exact definition of their role in cardiomyocytes. ${ }^{38,39}$

Ischemic inflammatory myocardial injury began during the period in which the blood supply was interrupted and increased during the period of coronary reperfusion ${ }^{40,41}$, along with a greater expression of COX-2 $2^{34} \mathrm{mRNA}$.

A study by Metais et $\mathrm{al}^{35}$ showed that increased COX2 levels in the microvasculature of pig ventricles were related to an increase in local vasoconstriction. This vasoconstriction, however, was inhibited by the use of a selective cyclooxygenase- 2 inhibitor. These results could explain, in part, the results of our current study, in which we observed biochemical signs of myocardial cytoprotection in acute myocardial infarction with treatment with a selective cyclooxygenase-2 inhibitor.

We found significantly lower values for the biochemical markers in the treated group, as compared to the control group, due to the use of rofecoxib. The values of CPK MB were obtained through the least sensitive detection method $(p=0.0445)$. Immunochemiluminescence with electronic reading, however, which was used to detect CPK MB mass $(\mathrm{p}=0.007)$ and troponin $\mathrm{I}(\mathrm{p}<0.001)$, is a more sensitive assay.

Although significant differences were observed between the groups for the biochemical markers, indicating possible myocardial cytoprotection in the setting of an acute ischemic stimulus, these differences were not observed in the quantification of the normoperfused, ischemic or infarcted tissue. ${ }^{21-23,42}$ 


\section{Clinical implications for the use of selective cyclooxyge- nase-2 inhibition and cardiovascular events}

Some questions are still open. Is there really a relationship between coxibs and the increase in the number of ischemic cardiac events? If so, how can we explain this pathophysiology? Are these pathophysiological mechanisms dependent on a coxib class effect, or are they only caused by a specific kind of selective cyclooygenase-2 inhibitor?

The VIGOR study (Vioxx Gastrointestinal Outcomes Research trial) was the first great study to discuss the presence of cardiovascular events with the use of icox-2. Meanwhile, results from a metanalysis ${ }^{43}$ involving rofecoxib showed that naproxen, used in the VIGOR study, has a protective effect, whereas the rofecoxib group went without this protection. Another important piece of information pertaining to this study was that the analyzed population consisted of patients with rheumatoid arthritis. These patients have a higher risk of cardiovascular events, and this compromises the results of the VIGOR study. On the other hand, a study ${ }^{44}$ of 150 patients using rofecoxib, who underwent isolated coronary artery bypass graft surgery, showed that there was no clinical evidence for a deleterious effect of rofecoxib on myocardium in these patients.

Differences in the chemical structures of the various coxibs result in different pharmacological and pharmacokinetic proprieties that could theoretically explain why one coxib is more toxic than another of the same class. There are no studies, however, that evaluate cardiovascular events and compare one coxib with another of the same class, which might support this theory. ${ }^{45}$ On the other hand, a study developed by Andersohn et al. ${ }^{46}$ in which patients with acute myocardial infarction were evaluated, suggested that the toxicity could be related to the entire coxib class. However, these authors compared icox-2 drugs to a nonselective COX inhibitor (diclofenac), similar to the VIGOR study.

Meanwhile, an experimental study conducted by Delgado et al. demonstrated that cyclooxygenase- 2 inhibition could attenuate the development of cardiac heart failure after myocardial lesions, as evidenced by improved left ventricular ejection fraction and a reduction in animal mortality. ${ }^{47}$

Further ongoing trials are investigating the newer coxibs as well as the older drugs, but unfortunately, they are mostly being performed in patients with rheumatoid arthritis, as in the CLASS and the TARGET studies. It is already known that rheumatoid arthritis itself is a risk factor for cardiac disease, most likely due to a chronic increase in circulating cytokine concentrations as well as in $\mathrm{C}$ reactive protein and other proatherogenic inflammatory markers, with activation of leucocytes in both processes. ${ }^{48}$

Another study showed that the use of icox- 2 was able to reduce endothelial oxidative stress and the generation of ionic forms (nitric oxide induced synthase), peroxynitrite and superoxide and the formation of interleukins 6 and 8 . These reductions in endothelial oxidative stress provoked improvement in endothelium-dependent vasodilatation, resulting in the improvement of heart failure disease. ${ }^{49}$ Moreover, an increase in serum VEGF (Vascular Endothelial Growth Factor) was not suppressed by treatment with icox-2 , indicating that VEGF was induced in a COX-2-independent manner. ${ }^{50,51}$

Recently, another experimental study ${ }^{52}$ showed, for the first time, a functional improvement with the administration of parecoxib, a selective COX-2 inhibitor, in an animal model of ischemic congestive heart failure. Confirming these findings, a functional improvement with COX-2 inhibitors in a model of non-ischemic heart failure was already shown and was paired with a significant reduction in mortality. ${ }^{46}$

Cumulative data currently suggest that the mechanisms of acute myocardial infarction and inflammation have different phases in which the same component (e.g., cyclooxygenase-2) can be beneficial in a given moment but have a different effect at another moment. Thus, further studies are needed to clarify the pathophysiological mechanisms linking inflammatory activity to acute myocardial infarction.

\section{CONCLUSION}

The results of this study have shown that the use of a specific cyclooxygenase-2 inhibitor, rofecoxib, might be beneficial in reducing the intensity of myocardial injury induced by acute coronary occlusion in dogs. New clinical studies related to endothelial dysfunction and inflammation are necessary, however, in order to elucidate the complete role of inflammatory mechanisms in acute myocardial infarction.

\section{REFERENCES}

1. Braunwald E, Kloner RA. Myocardial reperfusion: a double-edged sword? J Clin Invest. 1985;76(5):1713-9.

2. Jones SP, Lefer DJ. Myocardial Reperfusion Injury: Insights Gained from Gene-Targeted Mice. News Physiol Sci. 2000;15:303-8.
3. Mullane KM, Read N, Salmon JA, Moncada S. Role of leukocytes in acute myocardial infarction in anesthetized dogs: relationship to myocardial salvage by anti-inflammatory drugs. J Pharmacol Exp Ther. 1984;228(2):510-22. 
4. LeGal YM, Morrissey LL. Methylprednisolone interventions in myocardial infarction: a controversial subject. Can J Cardiol. 1990;6(9):405-10.

5. Roberts R, DeMello V, Sobel BE. Deleterious effects of methylprednisolone in patients with myocardial infarction. Circulation. 1976;53(3 Suppl):I204-6.

6. Azar RR, Rinfret S, Théroux P, Stone PH, Dakshinamurthy R, Feng YJ, Wu AH, Rangé G, Waters, et al. A randomized placebo-controlled trial to assess the efficacy of antiinflammatory therapy with methylprednisolone in unstable angina (MUNA trial). Eur Heart J. 2000;21(24):2026-32.

7. Sajadieh A, Wendelboe O, Hansen JF, Mortensen LS. Nonsteroidal anti-inflammatory drugs after acute myocardial infarction. DAVIT Study Group. Danish Verapamil Infarction Trial. Am J Cardiol. 1999. 15;83(8):1263-5,A9

8. Altman R, Luciardi HL, Muntaner J, Del Rio F, Berman SG, Lopez R, et al. Efficacy assessment of meloxicam, a preferential cyclooxygenase-2 inhibitor, in acute coronary syndromes without ST-segment elevation: the Nonsteroidal Anti-Inflammatory Drugs in Unstable Angina Treatment-2 (NUT-2) pilot study. Circulation. 2002. 9;106(2):191-5.

9. Gottlieb S. COX 2 inhibitors may increase risk of heart attack. BMJ. 2001.1;323(7311):471.

10. Pitt B, Pepine C, Willerson JT. Cyclooxygenase-2 inhibition and cardiovascular events. Circulation. 2002.9;106(2):167-9.

11. Warner JJ, Weideman RA, Kelly KC, Brilakis ES, Banerjee S, Cunningham F, et al. The Risk of Acute Myocardial Infarction With Etodolac is Not Increased Compared to Naproxen: A Historical Cohort Analysis of a Generic COX-2 Selective Inhibitor. J Cardiovasc Pharmacol Ther. 2008;13(4):252-60. Epub 2008 Sep 11.

12. Cunnington M, Webb D, Qizilbash N, Blum D, Mander A, Funk MJ, et al. Risk of ischaemic cardiovascular events from selective cyclooxygenase-2 inhibitors in osteoarthritis. Pharmacoepidemiol Drug Saf. 2008;17(6):601-8.

13. Sorensen R, Abildstrom SZ, Torp-Pedersen C, Gislason GH. Use of selective cyclooxygenase-2 inhibitors and nonselective nonsteroidal antiinflammatory drugs in high doses increases mortality and risk of reinfarction in patients with prior myocardial infarction. J Cardiovasc Nurs. 2008;23(1):14-9.

14. Gimbrone MA Jr, Topper JN, Nagel T, Anderson KR, Garcia-Cardeña G. Endothelial dysfunction, hemodynamic forces, and atherogenesis. Ann N Y Acad Sci. 2000;902:230-9.

15. Keerthisingam CB, Jenkins RG, Harrison NK, Hernandez-Rodriguez NA, Booth H, Laurent GJ, et al. Cyclooxygenase-2 deficiency results in a loss of the anti-proliferative response to transforming growth factorbeta in human fibrotic lung fibroblasts and promotes bleomycin-induced pulmonary fibrosis in mice. Am J Pathol. 2001;158(4):1411-22.

16. Gilroy DW, Colville-Nash PR, Willis D, Chivers J, Paul-Clark MJ, Willoughby DA. Inducible cyclooxygenase may have anti-inflammatory properties. Nat Med. 1999;5(6):698-701.

17. Saito T, Rodger IW, Hu F, Shennib H, Giaid A. Inhibition of cyclooxygenase-2 improves cardiac function in myocardial infarction. Biochem Biophys Res Commun. 2000;5;273(2):772-5.

18. Saito T, Rodger IW, Shennib H, Hu F, Tayara L, Giaid A. Cyclooxygenase-2 (COX-2) in acute myocardial infarction: cellular expression and use of selective COX-2 inhibitor. Can J Physiol Pharmacol. 2003;81(2):1149 .
19. Saito T, Rodger IW, Hu F, Robinson R, Huynh T, Giaid A. Inhibition of COX pathway in experimental myocardial infarction. J Mol Cell Cardiol. 2004 Jul;37(1):71-7.

20. Straino S, Salloum FN, Baldi A, Ockaili RA, Piro M, Das A, et al. Protective effects of parecoxib, a cyclo-oxygenase-2 inhibitor, in postinfarction remodeling in the rat. J Cardiovasc Pharmacol. 2007;50(5):571-7.

21. LaPointe MC, Mendez M, Leung A, Tao Z, Yang XP. Inhibition of cyclooxygenase- 2 improves cardiac function after myocardial infarction in the mouse. Am J Physiol Heart Circ Physiol. 2004;286(4):H141624.

22. Timmers L, Sluijter JP, Verlaan CW, Steendijk P, Cramer MJ, Emons $\mathrm{M}$, et al. Cyclooxygenase-2 inhibition increases mortality, enhances left ventricular remodeling, and impairs systolic function after myocardial infarction in the pig. Circulation. 2007;23;115(3):326-32.

23. Shinmura K, Tang XL, Wang Y, Xuan YT, Liu SQ, Takano H, et al Cyclooxygenase- 2 mediates the cardioprotective effects of the late phase of ischemic preconditioning in conscious rabbits. Proc Natl Acad Sci U S A. 2000;29;97(18):10197-202.

24. Rossoni G, Muscara MN, Cirino G, Wallace JL. Inhibition of cyclooxygenase- 2 exacerbates ischaemia-induced acute myocardial dysfunction in the rabbit. Br J Pharmacol. 2002;135(6):1540-6.

25. Rosner B. Fundamentals of Biostatistics. 1986. $2^{\text {nd }}$ edition. Boston, PWS Publishers.

26. Wolf K, Castrop H, Hartner A, Goppelt-Strübe M, Hilgers KF, Kurtz A. Inhibition of the rennin-angiotensin system upregulates cyclooxygenase-2 expression in the macula dense. Hypertension. 1999;34:503-07.

27. Ichihara A, Imig JD, Navar LG. Cyclooxygenase-2 modulates afferent arteriolar responses to increases in pressure. Hypertension. 1999;34[part 2]:843-47.

28. Brands MW, Hailman AE \& Fitzgerald SM. Long-term glucose infusion increases arterial pressure in dogs with cyclooxygenase-2 inhibition. Hypertension. 2001;37(2 Part 2):733-8.

29. Höcherl K, Dreher F, Kurtz A, Bucher M. Cyclooxygenase-2 inhibition attenuates lip polysaccharide-induced cardiovascular failure. Hypertension. 2002;40:943.

30. Verma S, Raj SR, Shewchuk L, Mather KJ, Anderson TJ. Cyclooxygenase-2 blockade does not impair endothelial vasodilator function in healthy volunteers. Circulation. 2001;104:2879-82.

31. Fredericks S, Merton GK, Lerena MJ, Heining P, Carter ND, Holt DW. Cardiac troponins and creatine kinase content of striated muscle in common laboratory animals. Clinica Chimica Acta. 2001;304:65-74.

32. Stanfield KM, Khan KN \& Gralinski MR. Localization of cyclooxygenase isozymes in cardiovascular tissue of dogs treated with naproxen. Veterinary Immunology and Immunopathology, 2001;80:309-14.

33. Zoldhelyi P, McNatt J, Xu XM, Loose-Mitchell D, Meidell RS, Clubb FJ Jr, et al. Prevention of arterial thrombosis by adenovirus-mediated transfer of cyclooxygenase gene. Circulation. 1996;93:10-7.

34. Gerhardt W \& Ljungdahl L. Detection of myocardial damage by seria measurements of cardiac troponin T, CK MBmass, and TROPT rapid test. Cardiovascular Drugs Therapy, 1997;11 [Suppl 1]:227-40. 
35. Métais C, Li J, Simons M, Sellke FW. Serotonin-induced coronary contraction increases after blood cardioplegia-reperfusion. Role of COX-2 expression. Circulation. 1999;100(19 Suppl):II328-34

36. Sajadieh A, Wendelboe O, Hansen JF \& the DAVIT Study Group. Nonsteroidal anti-inflammatory drugs after acute myocardial infarction. The American Journal of Cardiology. 1999;83:1263-65.

37. Azar RR, Rinfret S, Théroux P, Stone PH, Dakshinamurthy R, Feng YJ, et al. A randomized placebo-controlled trial to assess the efficacy of anti-inflammatory therapy with methylpredinisolone in unstable angina (MUNA Trial). European Heart Journal. 2000;21:2026-32.

38. Mendez M, LaPointe MC.. Trophic effects of the cyclooxygenase-2 product prostaglandin $\mathrm{E}_{2}$ in cardiac myocytes. Hypertension. 2002,39[part 2]:382-8.

39. Wong SC, Fukuchi M, Melnyk P, Rodger I, Giaid A. Induction of Cyclooxygenase-2 and Activation of Nuclear Factor-kB in Myocardium of Patients with Congestive Heart Failure. Circulation. 1998;98:1003.

40. Lango R, Anisimowicz L, Siebert J, Rogowski J, Bakowska A, Mrozinski $\mathrm{P}$ et al. IL-8 concentration in coronary sinus blood during early coronary reperfusion after ischemic arrest. European Journal of Cardio-thoracic Surgery. 2001;20:550-4.

41. Frangogiannis NG, Lindsey ML, Michael LH, Youker KA, Bressler $\mathrm{RB}$, Mendonza LH, et al. Resident cardiac mast cells degranulate and release preformed canine myocardial ischemic/reperfusion. Circulation. 1998;98:699-710.

42. Timm NH. Multivariate Analysis with Applications in Educations and Psychology. 1975. Monterrey, CA Brooks/Cole.

43. Jüni P, Nartey L, Reichenbach S, Sterchi R, Dieppe PA, Egger M. Risk of cardiovascular events and rofecoxib: cumulative meta-analysis. Lancet. 2004:364:2021-9.

44. Wong PS, Asmat A, Chan YH, Lee CN. A randomized, double-blind, placebo-controlled trial of a COX-2 inhibitor (Rofecoxib) in patients undergoing coronary artery bypass surgery. Interactive CardioVascular and Thoracic Surgery. 2006.5:101-4.

45. Praticò D, Dogné JM. Selective cyclooxygenase-2 inhibitors development in cardiovascular medicine. Circulation. 2005;112:1073-9.

46. Andersohn F, Suissa S, Garbe E. Use of first and second generation cyclooxygenase-2 selective nonsteroidal anti-inflammatory drugs and risk of acute myocardial infarction. Circulation. 2006;113:1950-7.

47. Colombo PC, Banchs JE, Celay S, Talreja A, Lachmann J, Malla S, et al. Endothelial cell activation in patients with decompensated heart failure. Circulation. 2005;111:58-62.

48. Sooriakumaran P. COX-2 inhibitors and the heart: are all coxibs the same? Postgraduated Medicine Journal. 2006;82:242-5.

49. Delgado RM 3rd, Nawar MA, Zewail AM, Kar B, Vaughn WK, Wu KK, et al. Cyclooxygenase-2 inhibitor treatment improves left ventricular function and mortality in a murine model of doxorubicin-induced heart failure. Circulation. 2004:109:1428-33.
50. Oshima M, Suzuki H, Guo X, Oshima H. Increased level of Serum Vascular Endothelial Growth Factor by long-term exposure to hipergravity. Exp. Anim. 2007. 56: 309-13.

51. Candelario-Jalil E, Mhadu N H, González-Falcón A, García-Cabrera M, Muñoz E, León OS, et al. Effects of the cyclooxygenase-2 inhibitor nimesulide on cerebral infarction and neurological deficits induced by permanent middle cerebral artery occlusion in the rat. Journal of Neuroinflammation. 2005,2:3

52. Abbate A, Salloum FN, Ockaili RA, Fowler III AA, Biondi-Zoccai GGL, Straino S, et al. Improvement of Cardiac Function With Parecoxib, A Cyclo-oxygenase-2 Inhibitor, in a Rat Model of Ischemic Heart Failure. Journal of Cardiovascular Pharmacology. 2007;49:416-8.

53. Adams JE 3rd, Abendschein DR, Jaffe AS. Biochemical markers of myocardial injury: Is MB Creatine kinase the choice for the 1990? Circulation. 1993;88:750-63.

54. Rozenman Y, Gotsman MS. The earliest diagnosis of acute myocardial infarction. Annu Rev Med. 1994;45:31-44.

55. Adams JE 3rd, Bodor GS, Dávila-Román VG, Delmez JA, Apple FS, Ladenson JH, et al. Cardiac Troponin I: a marker with high specificity for cardiac injury. Circulation. 1993;88:101-6.

56. Adams JE 3rd, Schechtman KB, Landt Y, Ladenson JH, Jaffe AS.. Comparable detection of acute myocardial infarction by creatine kinase MB isoenzyme and cardiac troponin I. Clinical Chemistry. 1994:40:1291-5.

57. Jolly SR, Kane WJ, Bailie MB, Abrams GD, Lucchesi BR. Canine myocardial reperfusion injury. Its reduction by the combined administration of superoxide dismutase and catalyses. Circulation Research. 1984:54:277-85

58. Chagas ACP. Óxido nítrico na isquemia miocárdica aguda: estudo experimental sobre a proteção miocárdica no modelo de oclusão/ reperfusão. Livre-Docência Tese.1996. Faculdade de Medicina da USP. Departamento de Cardiopneumologia - São Paulo, SP, Brasil.

59. Kloner RA, Ganote CE, Jennings RB. The "no reflow" phenomenon after temporary coronary occlusion in the dog. The Journal of Clinical Investigation. 1974;54:1496-8.

60. Fishbein MC, Meerbaun S, Rit J, Lado U, Kanmatsuse K, Mercier JC, et al. Early phase myocardial infarct size quantification: Validation of Triphenil Tetrazolium Chloride tissue enzyme staining technique. American Heart Journal. 1981;101:593-600.

61. Fung HB, Kirschenbaum HL. Selective cyclooxygenase-2 inhibitors for the Ttreatment of arthritis. Clin Ther. 1999.21(7):1131-57.

62. Scott LJ, Lamb HM. Rofecoxib. Drugs.1999;58(3):499-505.

63. Halpin RA, Geer LA, Zhang KE, Marks TM, Dean DC, Jones AN, et al. The absortption, distribution, metabolism, and excretion of rofecoxib, a potent and selective cyclooxygenase- 2 inhibitor, in rats and dogs. Drug Metabolism and Disposition. 2000;28:1244-54.

64. Guide for the Care and Use of Laboratory Animals. Institute of Laboratory Animal Resources. Commission on Life Sciences. National Research Council. National Academy Press Washington, D.C. 1996. 